\title{
Structural characterization of silk-polyurethane composite material for biomaterials using solid-state NMR
}

\begin{abstract}
Yasumoto Nakazawa ${ }^{1}$, Atsushi Asano ${ }^{2}$, Chikako T Nakazawa ${ }^{2}$, Toshihide Tsukatani ${ }^{3}$ and Tetsuo Asakura ${ }^{4}$
In this paper, we performed solid-state nuclear magnetic resonance (NMR) measurements, including $T_{1}{ }^{\mathrm{H}}$ and $T_{1 \rho}$, of silk fibroin (SF)/polyurethane (PU) composites to examine their possible use as a material for artificial vascular grafts. In the development of new artificial vascular grafts made from SF/PU, it is important to examine the miscibility of the composites and their molecular dynamics, because these properties are intimately involved in the resulting physical properties of the resulting vascular graft. The $T_{1}{ }^{\mathrm{H}}$ measurements showed that the domain size of the SF/PU =1:1 composite is smaller than the domain size of the 1:10 and 1:2 composites, indicating that the molecular miscibility between SF and PU are partially in close proximity, particularly in the SF/PU =1:1 composite. Additionally, we observed that the molecular motion of the soft segment of PU in the SF/PU composites becomes slow, suggesting that the soft segment of PU interacts with SF to some extent. These analyses provided basic structural information for the development of silk-based artificial vascular grafts using PU.
\end{abstract}

Polymer Journal (2012) 44, 802-807; doi:10.1038/pj.2012.119; published online 13 June 2012

Keywords: silk fibroin; small-diameter vascular graft; solid-state NMR; vascular regenerations

\section{INTRODUCTION}

Vascular grafts prepared from expanded polytetrafluoroethylene or polyethylene terephthalate fiber (Dacron) have been used clinically for many years for the revascularization of vascular grafts with inner diameters of $\geqq 6 \mathrm{~mm}$. However, replacement of vascular grafts with these synthetic materials for smaller vascular grafts of $<5 \mathrm{~mm}$ leads to a high incidence in graft failure mainly because of the early formation of thrombosis, especially when the distal anastomosis is below the knee. ${ }^{1}$ Therefore, in the field of surgical revascularization, the development of functional vascular grafts with inner diameters of $<5 \mathrm{~mm}$ is strongly desired. To overcome the early formation of thrombosis for small-diameter vascular grafts, various tissueengineered vascular grafts have been developed $^{2}$ and their utility and clinical experience have also been reported. ${ }^{3-6}$ However, there are still no commercially available grafts to date that fully satisfy the requirements for functional, small-diameter vascular grafts.

The silk fibroin (SF) from Bombyx mori has been used in biomedical applications, such as suturing, for centuries. SF consists of highly organized $\beta$-sheet structure in the crystalline region. ${ }^{3,4}$ Moreover, SF also has several semi-crystalline regions, which are responsible for its elasticity compared with fibers of similar tensile integrity. 5,6 We have already reported excellent results for the development of small-diameter vascular grafts made from $\mathrm{SF}^{7-10}$ These novel vascular grafts made from SF (length: $8 \mathrm{~mm}$; internal diameter: $1.5 \mathrm{~mm}$ ) improved the patency of the graft remarkably, that is, more than $85 \%$ patency remained after 1 year of implantation in rat abdominal aorta. ${ }^{89}$ Although the SF fiber is superior in patency compared with other synthetic materials used in grafts, it is difficult to use the SF alone as an artificial vascular graft because of its poor mechanical stability, such as its low yielding property and weakness against bending. In contrast, it is known that several types of polyurethanes (PUs) are satisfactory materials in solving thrombosis and operability problems because of their excellent elastic properties and their biocompatible, microporous structure. ${ }^{11,12}$

Responsibility, or the 'compliance' value, for the heart cycle is very important in a vascular graft. When the compliance value for the vascular graft made from SF fiber is lower than that of a native vascular graft, it is indicative of thrombosis or intimal thickening. PU has beneficial mechanical properties, including a high toughness against bending; however, the use of vascular grafts made from PU alone is occluded by thrombosis in spite of the fact the compliance value of $\mathrm{PU}$ is high enough to use in grafts. Therefore, the combination of SF and PU as a material in small-diameter vascular grafts should prove successful.

The miscibility of SF and PU will be a very important factor in using the SF/PU composites in artificial vascular grafts, because if phase separation occurs, an adequate fusion of the beneficial properties of SF and PU will not occur. Thus, to combine the beneficial

${ }^{1}$ Nature and Science Museum, Tokyo University of Agriculture and Technology, Tokyo, Japan; ${ }^{2}$ Department of Applied Chemistry, National Defense Academy, Yokosuka, Japan; ${ }^{3}$ Nicca Chemical Co., Ltd, Fukui, Japan and 4Department of Biotechnology, Tokyo University of Agriculture and Technology, Koganei, Japan 
elasticity of PU and the superior patency of SF, it is very important to know the miscibility parameters of SF/PU composites.

In this study, the miscibility and dynamics of PU/SF composite materials were investigated using solid-state nuclear magnetic resonance (NMR) techniques, because solid-state NMR is very useful in examining the homogeneity and the local molecular motion change of the PU/SF composite.

\section{MATERIALS AND METHODS}

\section{Materials}

An ether-polycarbonate copolymer PU dispersion in aqueous solution (Nicca Chemical Co., Fukui, Japan) was used for the PU sample. The glass-transition temperature, $\mathrm{Tg}$, of the dried PU sample was $\sim 223 \mathrm{~K}$. Silk cocoons produced by $B$. mori were placed in water at $95^{\circ} \mathrm{C}$, after which the threads were reeled. The dried silk threads were placed in a mixture of sodium carbonate $(0.08 \%$, $\mathrm{w} / \mathrm{v})$ and marseille soap $(0.12 \%, \mathrm{w} / \mathrm{v})$ at $95^{\circ} \mathrm{C}$ for $120 \mathrm{~min} \cdot{ }^{13-15}$ This process was repeated to completely remove the silk sericin from the raw silk fibers. The removal of silk sericin was checked by a scanning electron microscope (VE-7800, Keyence Co., Osaka, Japan). The degummed silk fibers were dissolved in a $9 \mathrm{M}$ lithium bromide solution to a concentration of $20 \mathrm{w} / \mathrm{v} \%$ at $60^{\circ} \mathrm{C}$ for $4 \mathrm{~h}$ and then dialyzed against distilled water for 3 days at $4{ }^{\circ} \mathrm{C}$ using a cellulose membrane (MWCO 14000). The final concentration of the fibroin/ water solution was $6.0 \mathrm{w} / \mathrm{v} \% .{ }^{16}$ For the preparation of the thin films of the $\mathrm{SF}$ and PU composite materials, the dispersion of $\mathrm{PU}$ in water and aqueous SF solution were mixed together in ratios of SF/PU = 1:1, 1:2 and 1:10 (w/w). The mixed solutions were then cast into polystyrene petri dishes and dried at room temperature.

\section{NMR measurements}

High-resolution solid-state ${ }^{13} \mathrm{C}$ NMR spectra were obtained using a Varian NMR system $400 \mathrm{WB}$ spectrometer by the combined use of cross-polarization (CP) and magic angle spinning (MAS) with a two-pulse phase modulation ${ }^{17}$ and a ${ }^{1} \mathrm{H}$ decoupling of $62 \mathrm{kHz}$. The pulse delay time, ${ }^{1} \mathrm{H} 90^{\circ}$ pulse, contact time and spinning rate were $5 \mathrm{~s}, 3 \mu \mathrm{s}, 2 \mathrm{~ms}$ and $8 \mathrm{kHz}$, respectively. The ${ }^{13} \mathrm{C}$ chemical shifts were measured relative to tetramethylsilane using the methine carbon signal at 29.47 p.p.m. for solid adamantine as an external standard. The ${ }^{1} \mathrm{H}$ spin-lattice relaxation times in the laboratory frame $\left(T_{1}{ }^{\mathrm{H}}\right)$ were indirectly measured from the well-resolved ${ }^{13} \mathrm{C}$ signals enhanced by a $\mathrm{CP}$ of $2 \mathrm{~ms}$ applied after the inversion-recovery pulse sequence for ${ }^{1} \mathrm{H}$. The values of the ${ }^{1} \mathrm{H}-{ }^{13} \mathrm{C}$ cross-relaxation time $\left(T_{\mathrm{CH}}\right)$ and $T_{1}{ }^{\mathrm{H}}$ in the rotating frame $\left(T_{1 \rho}{ }^{\mathrm{H}}\right)$ were obtained by CP contact time-dependent experiments.

\section{Differential-scanning calorimetry}

Temperature-modulated differential-scanning calorimetry measurements were performed using a DSC8500 system (Perkin-Elmer Inc., Waltham, MA, USA) under a dry nitrogen gas flow of $50 \mathrm{ml} \mathrm{min}^{-1}$. The samples were heated at $108 \mathrm{~K} \mathrm{~min}^{-1}$ from 210 to $430 \mathrm{~K}$ with a modulation period of $60 \mathrm{~s}$ and temperature amplitude.

\section{RESULTS AND DISCUSSION}

Miscibility analysis of the composite materials of SF and PU by using $T_{1}{ }^{\mathrm{H}}$ measurements

Figure 1 shows the ${ }^{13} \mathrm{C}$ CP/MAS NMR spectra of SF (A), PU (E) and the $\mathrm{SF} / \mathrm{PU}=1: 1$ (B), 1:2 (C) and 1:10 (D) composites. All of the peaks in each spectrum were assigned as shown in Figure 1 and Table 1.

The primary structure of SF contains multiple repeats of (AGSGAG) $)_{n}$, which make up $55 \%$ of the primary structure of silk fiber and form the insoluble quasi-crystalline $\mathrm{Cp}$-fraction after chymotrypsin cleavage. ${ }^{18}$ The SF has two distinct structures in the solid state: silk I before spinning and silk II after spinning. ${ }^{19,20}$

The PU is the solid sample of the dispersion in aqueous solution. In the spectra of the composite materials (Figures $1 \mathrm{~b}-\mathrm{d}$ ), all peaks are in the same positions as those of SF and PU (Figures 1a and c). All

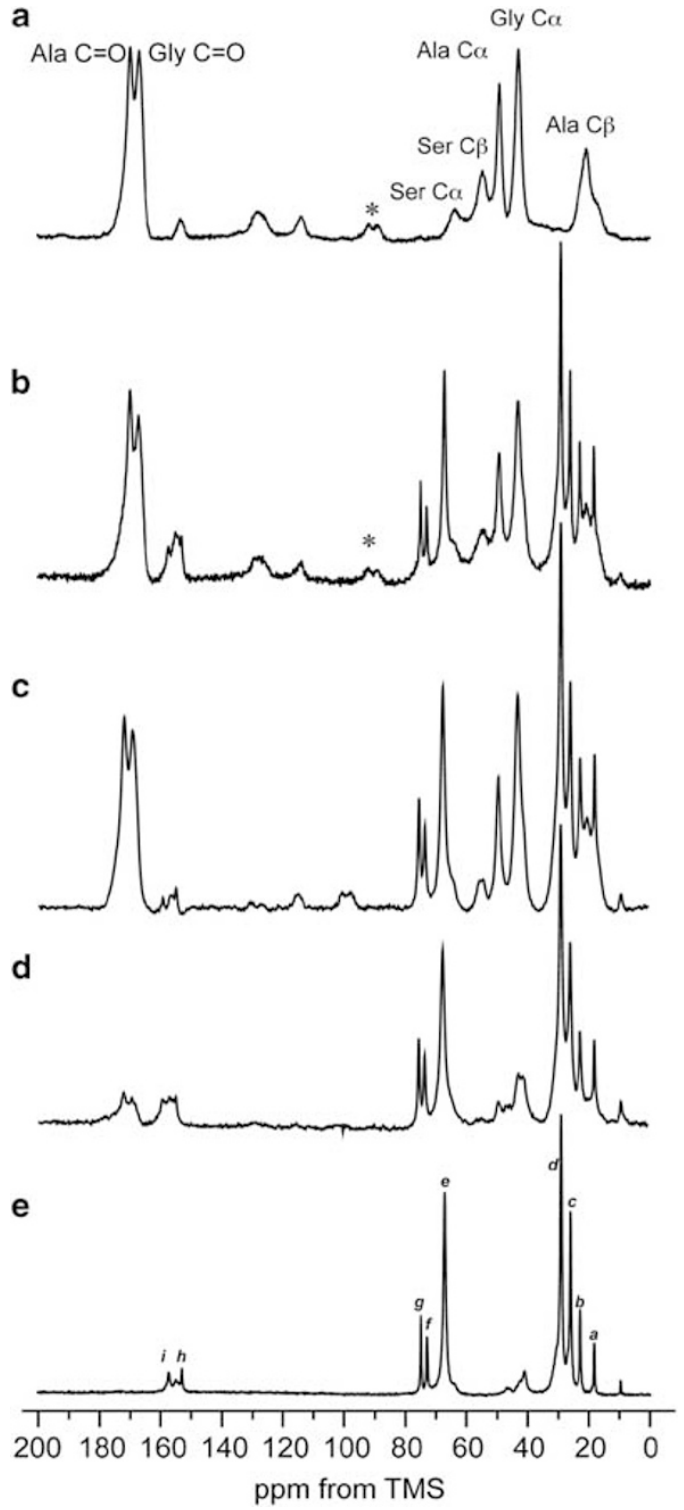

Figure 1 13CCP/MAS NMR spectra of the SF from $B$. mori (a), pure PU films (e) and the composite films from SF and PU at ratios of (1:1) (b), $(1: 2)(\mathbf{c})$ and $(1: 10)(d)$

peaks assigned to SF showed no shift after blending with PU. This consistency suggests that the excellent S-S curve property of SF remains unchanged even when mixed with PU, because the observation of no change in the chemical shift implies an unchanged threedimensional structure of SF, which is related to a beneficial S-S curve property at high strength. Similarly, the chemical shift values of PU were the same as those before blending with SF. The linewidth of peaks for PU, however, broadened somewhat after blending with SF, in particular, at a $\mathrm{CH}_{3}$ peak of $\sim 10$ p.p.m. and $\mathrm{CH}$ peaks of $\sim 75$ p.p.m. This indicates that the molecular motion of PU becomes slow after blending with SF.

To confirm miscibility, we performed differential-scanning calorimetry measurements (Figure 2). Figure 2 shows that every glasstransition temperature $(\mathrm{Tg})$ of $\mathrm{PU}$ for the composite materials at different ratios is the same as that of pure PU. The observation of two Tgs suggests two individual possibilities: either both polymers are not miscible on a $10-\mathrm{nm}$ scale or dynamic heterogeneity or good chain 
Table 1 Assignment of the ${ }^{13} \mathrm{C}$ CP/MAS NMR spectra of PU molecules

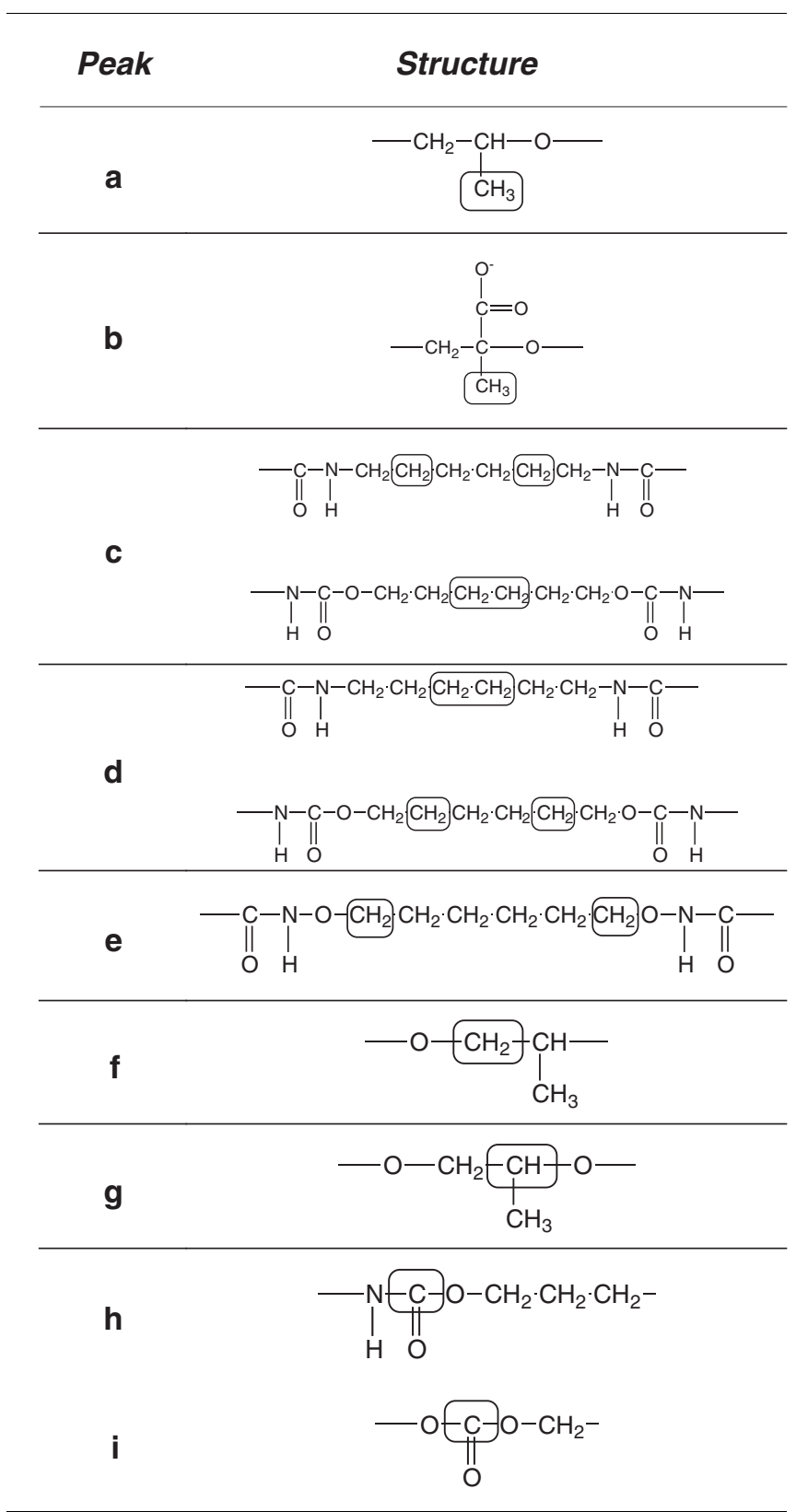

Each structure is compatible with the peaks in Figure 1.

connectivity is having a role. ${ }^{21}$ As stated above, the molecular motion of PU became slightly slow (linewidth became broad) after blending with SF, so the latter possibility is the most likely candidate. Furthermore, because PU has hard and soft segmental regions, the intrinsic calorimetric transition will be difficult to detect, particularly for PU in blends towing to its diluted concentration. Therefore, we employed ${ }^{1} \mathrm{H}$ spin-lattice relaxation time $\left(T_{1}{ }^{\mathrm{H}}\right)$ to detect the domain size, ${ }^{22-25}$ which is effective in detecting the domain size on a level of several $10 \mathrm{~nm}$ increments from $T_{1}{ }^{\mathrm{H}}$ even for the current PU/SF composite case.

Figure 3 shows logarithmic plots of the normalized peak intensities for the carbonyl groups of SF $(\boldsymbol{\Delta}, \boldsymbol{O})$ and methylene groups of the PU carbons $(\triangle, \bigcirc)$ vs the interval between $180^{\circ}$ and $90^{\circ}$ pulses.

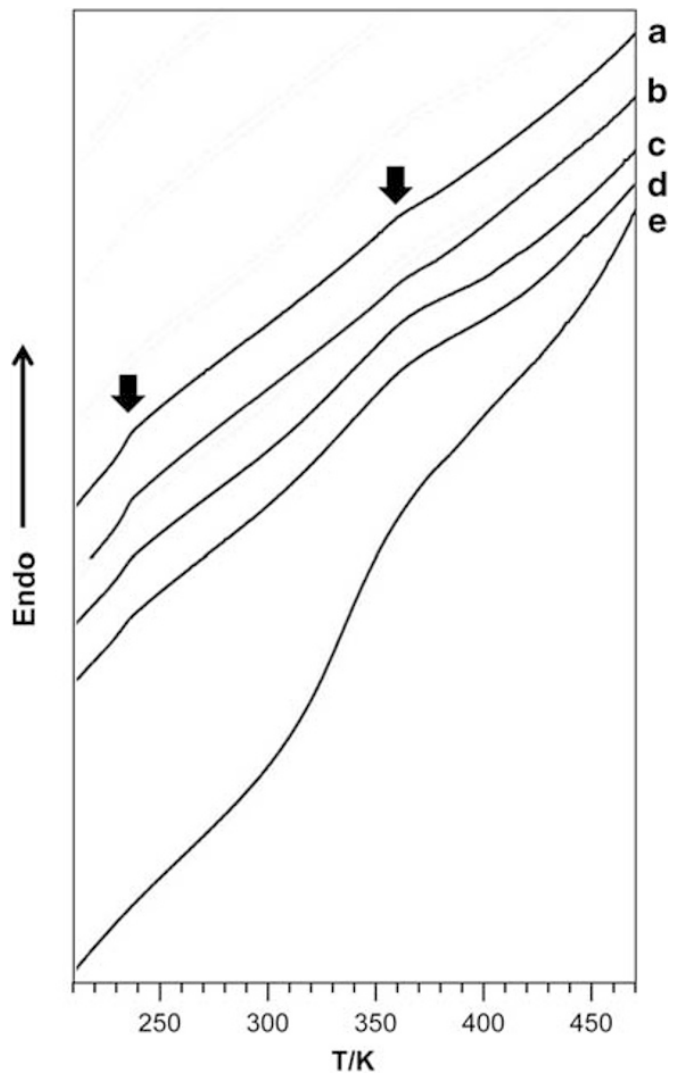

Figure 2 Differential-scanning calorimetry (DSC) curves of pure PU (a) and the composite materials of PU and SF. The ratios studied are 1:10 (b), 1:2 (c) and 1:1 (d). Pure SF is also shown in (e).

Figure $3 \mathrm{a}$ is obtained from the $\mathrm{SF} / \mathrm{PU}=1: 1$ blend and (b) from the 1:10 blend. The decay curves of pure SF and pure PU were single exponential, and they were depicted by dashed lines. The estimated $T_{1}{ }^{\mathrm{H}}$ values of pure SF and pure PU were 1.059 and $0.467 \mathrm{~s}$, respectively. However, their corresponding decay curves in the SF/PU composites were not single exponential and different from their original decays. The initial decay of PU is concave and is convex for SF. These decays became close to each other and showed singleexponential decay after $0.5 \mathrm{~s}$ elapsed. Thus, the observed decay curves are typical in the case of the existence of the effective ${ }^{1} \mathrm{H}$ spin diffusion. $^{22,23}$

The ${ }^{1} \mathrm{H}$ spin-diffusion affects ${ }^{1} \mathrm{H}$ spin-lattice relaxation times $\left(T_{1}{ }^{\mathrm{H}}\right.$ and $T_{1}{ }^{\mathrm{H}}$ ) and causes them to be non-exponential depending on both the proton densities in a system and its diffusive path length, which is the domain size of components. Therefore, if SF and PU in these composite materials are in completely separate states, the observed $T_{1}$ decays of SF and PU in SF/PU composites were the same as those of pure ones. In contrast, in a miscible blend, the observed $T_{1}$ decay of SF will coincide with that of PU because of the very fast spindiffusion process between the SF and PU domains.

Figure 3 shows that the $T_{1}{ }^{\mathrm{H}}$ curve of SF changes significantly and becomes close to that of $\mathrm{PU}$ although both $T_{1}{ }^{\mathrm{H}}$ curves are not completely identical to each other. This observation indicates that $\mathrm{SF} / \mathrm{PU}$ composites are not homogeneous on a molecular level, but they are partially compatible. In other words, it is possible that these molecules are interacting in these composite materials.

The observed $T_{1}{ }^{\mathrm{H}}$ curves were successfully fitted using the assumption of the two-spin system with the insufficient ${ }^{1} \mathrm{H}$ spin 

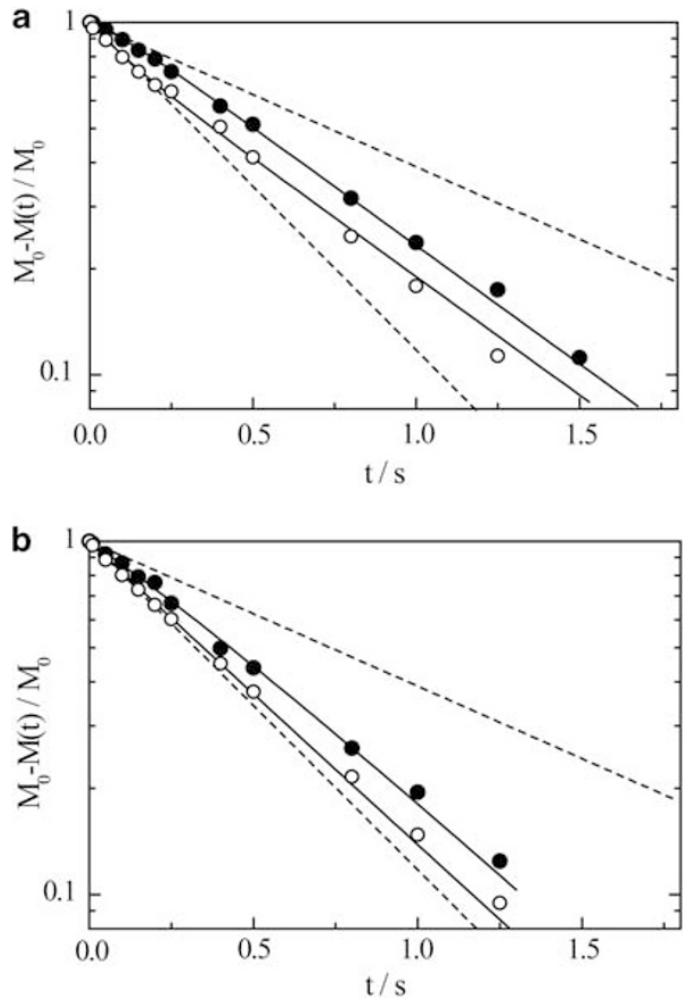

Figure 3 The observed plots for $T_{1}{ }^{\mathrm{H}}$ determination of the composite materials of SF/PU at ratios of 1:1 (a) and 1:10 (b). The open and filled circle symbols indicate the $\mathrm{CH}_{2}$ peak from PU molecules (67 p.p.m.) and the $\mathrm{C}=0$ peak from SF (170 p.p.m.), respectively. Each solid line is calculated using Equation (1) on the assumption of the two-spin system model. The dashed lines represent the relaxation curves of pure PU $\left(T_{1}{ }^{\mathrm{H}}=0.467 \mathrm{~s}\right)$ and pure SF $\left(T_{1}{ }^{\mathrm{H}}=1.059 \mathrm{~s}\right)$, respectively.

diffusion rate $k^{22,26}$ The two proton magnetizations $M_{\mathrm{A}}(t)$ and $M_{\mathrm{B}}(t)$, which are indirectly observed from ${ }^{13} \mathrm{C}$ signals, are expected as follows: ${ }^{22,23}$

$$
\frac{\mathrm{d}}{\mathrm{d} t}\left[\begin{array}{l}
M_{\mathrm{A}}(t) \\
M_{\mathrm{B}}(t)
\end{array}\right]=\left[\begin{array}{cc}
-\xi_{\mathrm{A}} & f_{\mathrm{A}} k \\
f_{\mathrm{B}} k & \xi_{\mathrm{B}}
\end{array}\right]\left[\begin{array}{c}
M_{\mathrm{A}}(t) \\
M_{\mathrm{B}}(t)
\end{array}\right]
$$

where $\xi_{A}=K_{\mathrm{A}}+f_{\mathrm{B}} k$ and $\xi_{\mathrm{B}}=K_{\mathrm{B}}+f_{\mathrm{A}} k$. Symbols A and B denote the ${ }^{1} \mathrm{H}$ spins of SF and PU, respectively. Parameters $K$ and $f$ are the ${ }^{1} \mathrm{H}$ relaxation rate $\left(1 / T_{1}{ }^{\mathrm{H}}\right)$ and ${ }^{1} \mathrm{H}$ molar fraction in the composite, respectively. The sum of $f_{\mathrm{A}}$ and $f_{\mathrm{B}}$ is equal to 1 . The proton mole fraction $f_{\mathrm{A}}$ is approximately equal to the mixing ratio for the current $\mathrm{SF} / \mathrm{PU}$ composites.

The 'best-fit' curves are depicted as solid lines in Figure 3. The 'best-fit' lines are in good agreement with the observed data points. The estimated $K_{\mathrm{A}}$ and $K_{\mathrm{B}}$ for $\mathrm{SF} / \mathrm{PU}=1: 1$ composites are $0.89 \mathrm{~s}^{-1}$ $\left(T_{1 \mathrm{~A}}=1.14 \mathrm{~s}\right)$ and $2.36 \mathrm{~s}^{-1}\left(T_{1 \mathrm{~B}}=0.42 \mathrm{~s}\right)$ with $k=7.24 \mathrm{~s}^{-1}$, respectively. Similarly, for the SF/PU $=1: 10$ composite, $K_{\mathrm{A}}$ and $K_{\mathrm{B}}$ are $1.48 \mathrm{~s}^{-1}\left(T_{1 \mathrm{~A}}=0.68 \mathrm{~s}\right)$ and $2.01 \mathrm{~s}^{-1}\left(T_{1 \mathrm{~B}}=0.50 \mathrm{~s}\right)$ with $k=1.75 \mathrm{~s}^{-1}$, respectively.

The maximum diffusive path length $(r)$ is calculated using the spin-diffusion rate $k^{22-25}$ The maximum diffusive path length for three dimensions is obtained by the typical solution of the diffusion equation as $r=\sqrt{6 D / k}$. We employed the average value $\left(700 \mathrm{~nm}^{2} \mathrm{~s}^{-1}\right)$ of the typical diffusion coefficient $D$ range of $500-1000 \mathrm{~nm}^{2} \mathrm{~s}^{-1}$ to estimate the domain size. ${ }^{23-25}$

The estimated domain size, $r, K$ and $k$ values from $T_{1}{ }^{\mathrm{H}}$ analysis for every composite are summarized in Table 2. The $r$ values for
Table $2 T_{1}{ }^{\mathrm{H}}$ values of $\mathrm{SF} \mathrm{C}=\mathrm{O}$ and $\mathrm{PU} \mathrm{OCH}_{3}$ of each composite

\begin{tabular}{lccc}
\hline & $1: 1$ & $1: 2$ & $1: 10$ \\
\cline { 2 - 4 } SF:PU & SF CO/PU OCH & SF CO/PU OCH & SF CO/PU OCH \\
\hline $1 / K_{\mathrm{A}}\left(T_{1}{ }^{\mathrm{H}}(\mathrm{SF})\right)$ & 1.14 & 0.83 & 0.68 \\
$1 / \mathrm{K}_{\mathrm{B}}\left(T_{1}{ }^{\mathrm{H}}(\mathrm{PU})\right)$ & 0.42 & 0.52 & 0.50 \\
$k$ & 7.24 & 1.94 & 1.75 \\
$r$ & $24 \mathrm{~nm}$ & $30 \mathrm{~nm}$ & $50 \mathrm{~nm}$ \\
\hline
\end{tabular}

Abbreviations: PU, polyurethane; SF, silk fibroin.

$\mathrm{SF} / \mathrm{PU}=1: 1,1: 2$, and 1:10 composites were calculated to be 24,30 and $50 \mathrm{~nm}$, respectively. The estimated domain sizes are satisfactorily small enough for ${ }^{1} \mathrm{H}$ spin diffusion to affect $T_{1}{ }^{\mathrm{H}}$ but not sufficient to have an identical $T_{1}{ }^{\mathrm{H}}$ decay for both components. ${ }^{22,23}$ The $r$ value of $24 \mathrm{~nm}$ for the $\mathrm{SF} / \mathrm{PU}=1: 1$ composite is smaller than those of the 1:10 and 1:2 composite materials. This estimation indicates that SF and PU are partially in close proximity, particularly in the $\mathrm{SF} / \mathrm{PU}=1: 1$ composite, indicating there is a portion of the molecules that contact each other through an intermolecular interaction, such as through hydrogen bonding.

Molecular dynamics analysis of the composite materials with SF and PU using $T_{\mathrm{CH}}$ and $T_{1 \rho}$ measurements

From the $T_{1} \mathrm{H}$ observations, we deduced the possible existence of the partially interacting portions of SF and PU. Furthermore, the ${ }^{13} \mathrm{C}$ CPMAS NMR spectra showed the linewidth change of PU with SF as stated previously. The existence of the interaction and the change in dynamics affects the cross-relaxation rate $\left(1 / T_{\mathrm{CH}}\right)$ between ${ }^{1} \mathrm{H}$ and ${ }^{13} \mathrm{C}$ for both components. To confirm the change in the molecular motion of each component, we measured the $\mathrm{CP}$ contact timedependent ${ }^{13} \mathrm{C}$ NMR spectra. The $T_{1 \rho}{ }^{\mathrm{H}}$ were also estimated from the CP-dependent experiments simultaneously. The plots of peak intensities for pure PU against the CP contact time are shown in Figure 4 for two characteristic peaks of PU.

The solid lines in Figure 4 were obtained from the least-square fit of the conventional equation for the carbon magnetization behavior $M^{\mathrm{C}}(t)$ at various $\mathrm{CP}$ contact times as follows: ${ }^{22,27}$

$$
M^{\mathrm{C}}(t)=\frac{M^{\mathrm{Max}} e^{-t / T_{1 \rho e}^{\mathrm{H}}-\mathrm{t} / T_{\mathrm{CH}}}}{T_{\mathrm{CH}} 1 / T_{\mathrm{CH}}-1 / T_{1 \rho}^{\mathrm{H}}}
$$

Here, $M^{\mathrm{Max}}$ is the maximum value of carbon magnetization. The $T_{\mathrm{CH}}$ and $T_{1 \rho}{ }^{\mathrm{H}}$ values of PU and SF are tabulated in Table 3.

Figure 4 shows that the simulated curves are in excellent agreement with the observed data points. Figure 4a was obtained from the carbon signal of the soft segment of pure PU at 75 p.p.m. (OCH group), and Figure $4 \mathrm{~b}$ was obtained from the hard segment of pure $\mathrm{PU}$ at 67 p.p.m. $\left(\mathrm{OCH}_{2}\right.$ group). For the soft segment of pure PU, the obtained $T_{1 \rho}{ }^{\mathrm{H}}$ value was $42.3 \mathrm{~ms}$ and that for the hard segment was $5.7 \mathrm{~ms}$. Furthermore, the $T_{\mathrm{CH}}$ values for soft and hard segments were 2.3 and $0.9 \mathrm{~ms}$, respectively. These observations suggest that the large $T_{1 \rho}$ value relates to the rapid molecular motion of the soft segment and the short $T_{1 \rho}{ }^{\mathrm{H}}$ value corresponds to the slow motion of the hard segment of PU. In addition, the $T_{\mathrm{CH}}$ obtained from the hard segment is shorter than that from the soft segment. This is because the cross relaxation occurs more quickly in rigid states: the rate $\left(1 / T_{\mathrm{CH}}\right)$ of the hard segment is greater than that of the soft segment. Figure 5 shows the comparison of the $T_{\mathrm{CH}}$ and $T_{1 \rho}{ }^{\mathrm{H}}$ values in each group of three types of composite materials. The plots of open and filled symbols indicate SF ( $O$ : Ala $C=O$; $\square$ : GlyC $\alpha ; \square$ : Ala $C \alpha$ ) and PU 

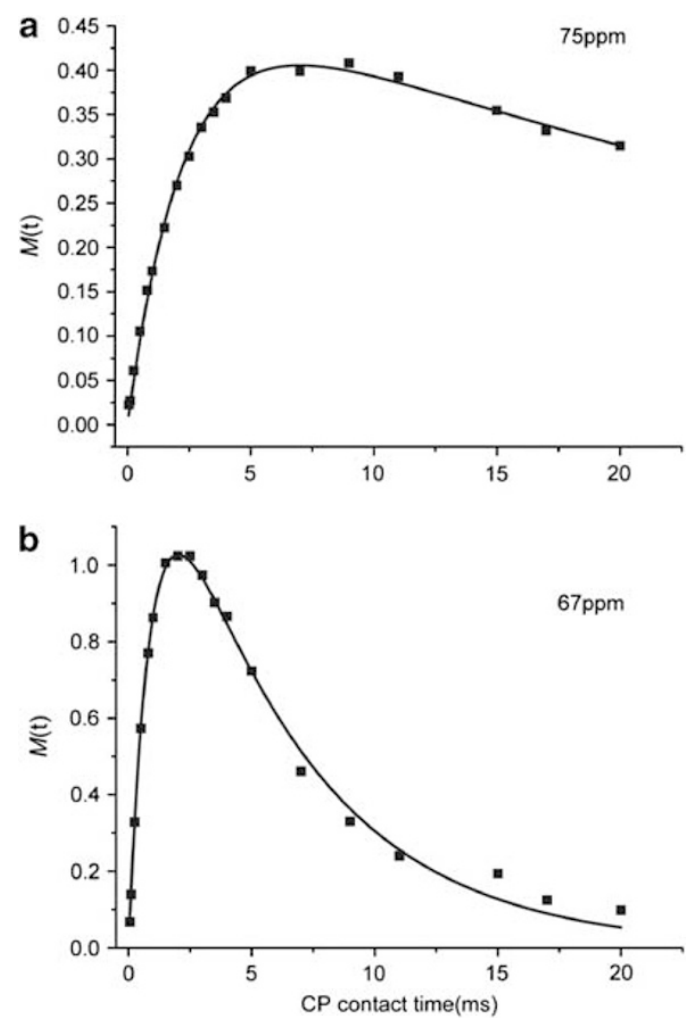

Figure 4 The spin-lattice relaxation times for protons in the rotating flames $\left(T_{1 \rho}{ }^{\mathrm{H}}\right)$ obtained by the peaks at 75 p.p.m. (a) and 67 p.p.m. (b) from PU. The solid lines are fitted curves obtained using Equation (2).

Table 3 Results of the $T_{\mathrm{CH}}$ and $T_{1 \rho}{ }^{\mathrm{H}}$ values of $\mathrm{PU}$ and SF molecules of each composite

\begin{tabular}{|c|c|c|c|c|c|c|}
\hline \multirow[b]{2}{*}{ SF:PU ratio } & \multicolumn{2}{|c|}{$\begin{array}{l}\text { Hard segment } \mathrm{CH}_{2} \\
\quad \text { (67 p.p.m.) }\end{array}$} & \multicolumn{2}{|c|}{$\begin{array}{l}\text { Soft segment } \mathrm{CH}_{2} \\
\text { (73 p.p.m.) }\end{array}$} & \multicolumn{2}{|c|}{$\begin{array}{c}\text { Soft segment } \mathrm{CH} \\
\text { (75 p.p.m.) }\end{array}$} \\
\hline & $T_{C H}$ & $T_{1 \rho}$ & $T_{C H}$ & $T_{1 \rho}$ & $T_{C H}$ & $T_{1 \rho}$ \\
\hline \multicolumn{7}{|l|}{$P U$} \\
\hline $0: 10$ & 0.9 & 5.7 & 1.8 & 31.6 & 2.3 & 42.3 \\
\hline $1: 10$ & 0.9 & 5.0 & 1.7 & 24.4 & 1.9 & 32.7 \\
\hline $1: 2$ & 0.7 & 5.0 & 1.1 & 20.9 & 1.1 & 26.4 \\
\hline $1: 1$ & 0.8 & 5.6 & 0.9 & 29.3 & 1.1 & 35.1 \\
\hline
\end{tabular}

Hard segment Ala $C=0$ Hard segment Ala C $\alpha$ Hard segment Gly Ca (170p.p.m.) (49p.p.m.) (43 p.p.m.)

\begin{tabular}{|c|c|c|c|c|c|c|}
\hline \multirow[b]{2}{*}{ SF:PU ratio } & & \multicolumn{2}{|c|}{ (49p.p.m.) } & \multicolumn{2}{|c|}{ (43 p.p.m.) } \\
\hline & $T_{C H}$ & $T_{1 \rho}$ & $T_{C H}$ & $T_{1 \rho}$ & $T_{C H}$ & $T_{1 \rho}$ \\
\hline \multicolumn{7}{|l|}{$S F$} \\
\hline $1: 10$ & 0.6 & 7.6 & 0.4 & 7.4 & 0.4 & 8.0 \\
\hline $1: 2$ & 0.6 & 9.0 & 0.9 & 9.2 & 0.9 & 9.2 \\
\hline $1: 1$ & 0.6 & 9.5 & 0.9 & 9.2 & 0.9 & 9.1 \\
\hline 10:0 & 0.7 & 13.2 & 0.7 & 13.6 & 0.7 & 13.5 \\
\hline
\end{tabular}

Abbreviations: PU, polyurethane; SF, silk fibroin.

67 p.p.m. $\left(\mathrm{CH}_{2}\right.$ in hard segment); $\boldsymbol{\Delta}$ : 75 p.p.m. ( $\mathrm{CH}$ in soft segment); $\mathbf{\square}$ : 73 p.p.m. $\left(\mathrm{CH}_{2}\right.$ in soft segment)) peaks. For the hard segment of PU, both $T_{\mathrm{CH}}$ and $T_{1 \rho}{ }^{\mathrm{H}}$ values did not change significantly for the entire compositions, indicating that the hard segment of $\mathrm{PU}$ moves individually and is not influenced by SF in SF/PU composites.
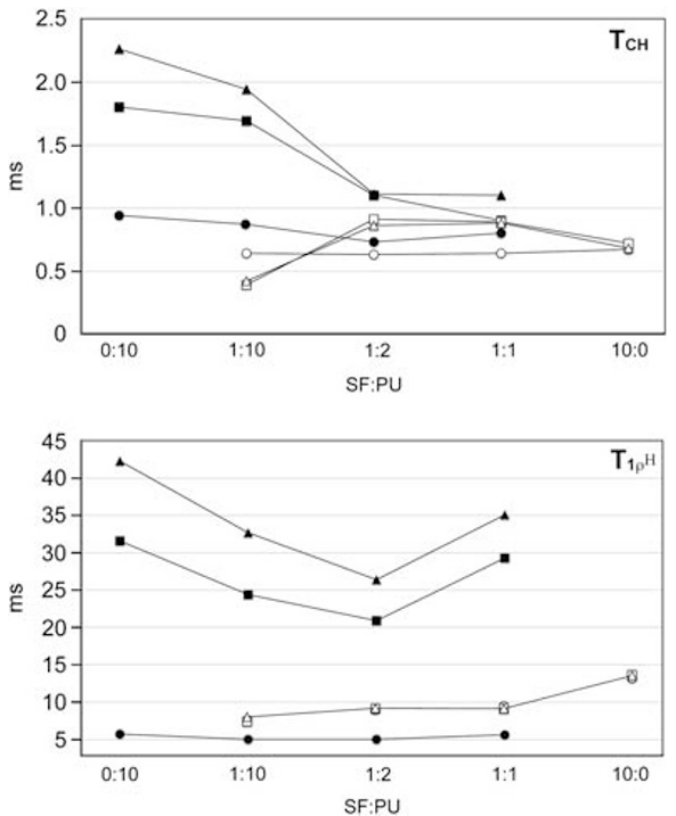

Figure 5 The comparison of the $T_{1 \rho}{ }^{\mathrm{H}}$ values in each group of three types of composite materials. Open and filled symbols indicate $\mathrm{SF}(\mathrm{O}$ : Ala $\mathrm{C}=0$; $\square$ : GlyC $\alpha ; \square$ : Ala $\mathrm{C} \alpha$ ) and PU (- 67 p.p.m. $\left(\mathrm{CH}_{2}\right.$ in hard segment); $\boldsymbol{\Delta}$ 75 p.p.m. ( $\mathrm{CH}$ in soft segment); $\mathbf{\square}$ : 73 p.p.m. $\left(\mathrm{CH}_{2}\right.$ in soft segment)) peaks, respectively.

However, the $T_{1 \rho}{ }^{\mathrm{H}}$ values of SF slightly decreased after blending with PU. The $T_{\mathrm{CH}}$ values of Ala $\mathrm{C}=\mathrm{O}$ group remained unchanged, but those of the Ala and Gly $\mathrm{C} \alpha$ carbons were distributed randomly and shifted slightly.

In contrast, the $T_{\mathrm{CH}}$ and $T_{1 \rho}{ }^{\mathrm{H}}$ values for the soft segment of PU decreased dramatically upon an increase in the SF concentration. This observation indicates that the molecular motion of the soft segment of PU is significantly affected and becomes slow by its interaction with SF in the composite. Especially, the decrease in the $T_{\mathrm{CH}}$ value supports the increase in rigidity and/or proton density for the soft segment of PU. Thus, it is suggested that the soft segment of PU interacts with SF to some extent.

Moreover, it is noteworthy that the $T_{1 \rho}{ }^{\mathrm{H}}$ of the soft segment of PU at the $\mathrm{SF} / \mathrm{PU}=1: 1$ composition increased compared with that of the 1:2 composition. According to the results of $T_{\mathrm{CH}}$, the molecular motion at the 1:1 composition is still slow, because the cross relaxation is very sensitive to its rigidity. Therefore, the increase in $T_{1 \rho}{ }^{\mathrm{H}}$ for the soft segment of PU at the 1:1 composition is not only due to the mobility change but also most likely due to the difference in the domain size. The smaller domain size $(24 \mathrm{~nm})$ in comparison with the other compositions $(30-50 \mathrm{~nm})$ presumably causes a change in the proton density and the motional mode around the soft segment of PU.

\section{CONCLUSIONS}

In this study, we elucidated the molecular dynamics, domain size and intermolecular interaction of the composite materials of SF and PU for the development of biomaterials, such as artificial vascular grafts. The solid-state ${ }^{13} \mathrm{C} \mathrm{CP/MAS} \mathrm{NMR} \mathrm{and} \mathrm{relaxation-time} \mathrm{experiments}$ were very useful in determining the change of dynamics and

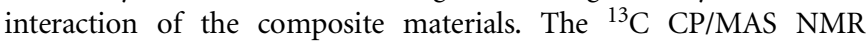
spectra showed that the structures of composites in several ratios were the same as that of before mixing. As for the $T_{1}{ }^{\mathrm{H}}$ measurements, the estimated domain size for $\mathrm{SF} / \mathrm{PU}=1: 1,1: 2$, and 1:10 composites 
were calculated to be 24,30 and $50 \mathrm{~nm}$, respectively. The domain size of $24 \mathrm{~nm}$ for the SF/PU =1:1 composite is much smaller than those domain sizes of the 1:10 and 1:2 composites. This result indicated that the molecular miscibility between SF and PU are partially in close proximity particularly in the $\mathrm{SF} / \mathrm{PU}=1: 1$ composite, indicating there is some intermolecular interaction between SF and PU, such as a hydrogen bonding interaction. In addition, differences in the molecular motion between the hard and soft segments in the PU were detected, suggesting that the soft segment of PU interacts with SF to some extent.

\section{ACKNOWLEDGEMENTS}

This work was supported by a Grant-in-Aid for Scientific Research C (23500512) from the Japan Society for the Promotion of Science (JSPS). In addition, this work was partially supported by a grant from the Ministry of Agriculture, Forestry and Fisheries of Japan (Agri-Health Translational Research Project).

1 Pawlowski, K. J., Rittgers, S. E., Schmidt, S. P. \& Bowlin, G. L. Endothelial cell seeding of polymeric vascular grafts. Front. Biosci. 9, 1412-1421 (2004).

2 Langer, L. \& Langer, B. The subepithelial connective tissue graft for treatment of gingival recession. Dent. Clin. North Am. 37, 243-264 (1993).

3 Suzuki, Y., Aoki, A., Nakazawa, Y., Knight, D. P. \& Asakura, T. Structural analysis of the synthetic peptide (Ala-Gly-Ser-Gly-Ala-Gly) 5 , a model for the crystalline domain of Bombyx mori silk fibroin, studied with ${ }^{13} \mathrm{C}$ CP/MAS NMR, REDOR, and statistical mechanical calculations. Macromolecules 43, 9434-9440 (2010).

4 Suzuki, Y., Takahashi, R., Shimizu, T., Tansho, M., Yamauchi, K., Williamson, M. P. \& Asakura, T. Intra- and intermolecular effects on $1 \mathrm{H}$ chemical shifts in a silk mode Peptide determined by high-field solid state $1 \mathrm{H}$ NMR and empirical calculations. J. Phys. Chem. B 113, 9756-9761 (2009).

5 Altman, G. H., Horan, R. L., Lu, H. H., Moreau, J., Martin, I., Richmond, J. C. \& Kaplan, D. L. Silk matrix for tissue engineered anterior cruciate ligaments. Biomaterials 23, 4131-4141 (2002).

6 Altman, G. H., Diaz, F., Jakuba, C., Calabro, T., Horan, R. L., Chen, J., Lu, H., Richmond, J. \& Kaplan, D. L. Silk-based biomaterials. Biomaterials 24, 401-416 (2003).

7 Sato, M., Nakazawa, Y., Takahashi, R., Tanaka, K., Sata, M., Aytemiz, D. \& Asakura, T. Small-diameter vascular grafts of Bombyx mori silk fibroin prepared by a combination of electrospinning and sponge coating. Mater. Lett. 64, 1786-1788 (2010).

8 Enomoto, S., Sumi, M., Kajimoto, K., Nakazawa, Y., Takahashi, R., Takabayashi, C., Asakura, T. \& Sata, M. Long-term patency of small-diameter vascular graft made from fibroin, a silk-based biodegradable material. J. Vasc. Surg. 51, 155-164 (2010).

9 Nakazawa, Y., Sato, M., Takahashi, R., Aytemiz, D., Takabayashi, C., Tamura, T., Enomoto, S., Sata, M. \& Asakura, T. Development of Small-Diameter Vascular Grafts Based on Silk Fibroin Fibers from Bombyx mori for Vascular Regeneration. J. Biomater. Sci. Polym. Ed. 22, 195-206 (2011).
10 Yagi, T., Sato, M., Nakazawa, Y., Tanaka, K., Sata, M., Itoh, K., Takagi, Y. \& Asakura, T. Preparation of double-raschel knitted silk vascular grafts and evaluation of short-term function in a rat abdominal aorta. J. Artif. Organs. 14, 89-99 (2011).

11 Xu, W., Zhou, F., Ouyang, C., Ye, W., Yao, M. \& Xu, B. Mechanical properties of small-diameter polyurethane vascular grafts reinforced by weft-knitted tubular fabric. J. Biomed. Mater. Res. A 92, 1-8 (2010).

12 Eberhart, A., Zhang, Z., Guidoin, R., Laroche, G., Guay, L., De La Faye, D., Batt, M. \& King, M. W. A new generation of polyurethane vascular prostheses: rara avis or ignis fatuus? J. Biomed. Mater. Res. 48, 546-558 (1999).

13 Asakura, T., Watanabe, Y. \& Itoh, T. NMR of silk fibroin. 3. Assignment of carbonyl carbon resonances and their dependence on sequence and conformation in Bombyx mori silk fibroin using selective isotopic labeling. Macromolecules 17, 2421-2426 (1984).

14 Demura, M. \& Asakura, T. Immobilization of glucose oxidase with Bombyx mori silk fibroin by only stretching treatment and its application to glucose sensor. Biotechnol. Bioeng. 33, 598-603 (1989).

15 Ishida, M., Asakura, T., Yokoi, M. \& Saito, H. Solvent- and mechanical-treatmentinduced conformational transition of silk fibroins studied by high-resolution solid-state ${ }^{13} \mathrm{C}$ NMR spectroscopy. Macromolecules 23, 88-94 (1990).

16 Makaya, K., Terada, S., Ohgo, K. \& Asakura, T. Comparative study of silk fibroin porous scaffolds derived from salt/water and sucrose/hexafluoroisopropanol in cartilage formation. J. Biosci. Bioeng. 108, 68-75 (2009).

17 Bennett, A. E., Rienstra, C. M., Auger, M., Lakshmi, K. V., Griffin, R. \& Heteronuclear, G. decoupling in rotating solids. J. Chem. Phys. 103, 6951-6958 (1995).

18 Asakura, T. \& Kaplan, D. L. Silk production and processing. in: Encyclopedia of Agricultural Science (ed. Arutzen, C. J. ) 1-11 (Academic Press, New York, 1994).

19 Asakura, T., Ohgo, K., Komatsu, K., Kanenari, M. \& Okuyama, K. Refinement of Repeated b-turn Structure for Silk I Conformation of Bombyx mori Silk Fibroin Using $13 \mathrm{C}$ Solid-State NMR and X-ray Diffraction Methods. Macromolecules 38, 7397-7403 (2005).

20 Asakura, T. Ashida, J., Yamane, T. Kameda, T. Nakazawa, Y, Ohgo, K. \& Komatsu, K. A repeated b-turn structure in poly(Ala-Gly) as a model for silk I of Bombyx mori silk fibroin studied with two-dimensional spin-diffusion NMR under off magic angle spinning and rotational echo double resonance. J. Mol. Biol. 306, 291-305 (2001).

21 Gaikwad, A. N., Wood, E. R., Ngai, T. \& Lodge, T. P. Two calorimetric glass transitions in miscible blends containing poly(ethylene oxide). Macromolecules 41, 2502-2508 (2008).

22 Stejskal, E. O., Schaefer, J., Sefcik, M. D. \& Mckay, R. A. Magic-Angle C-13 nuclear magnetic-resonance study of the compatibility of solid polymeric blends. Macromolecules 14, 275-279 (1981).

23 Asano, A. \& Takegoshi, K. in: Solid State NMR of Polymers (eds Ando, I. \& Asakura, T.) 351-414 (Elsevier Science B. V., Amsterdam, The Netherlands, 1998).

24 VanderHart, D. L. \& McFadden, G. B. Some perspectives on the interpretation of proton NMR spin diffusion data in terms of polymer morphologies. Solid State Nucl. Magn. Reson. 7, 45-66 (1996).

25 Demco, D. E., Johansson, A. \& Tegenfeldt, J. Proton spin diffusion for spatial heterogeneity and morphology investigations of polymers. Solid State Nucl. Magn. Reson. 4, 13-38 (1995).

26 Tsuchiya, A., Sotome, S., Asou, Y., Kikuchi, M., Koyama, Y., Ogawa, T., Tanaka, J. \& Shinomiya, K. Effects of pore size and implant volume of porous hydroxyapatite/ collagen $(\mathrm{HAp} / \mathrm{Col})$ on bone formation in a rabbit bone defect model. J. Med. Dent. Sci. 55, 91-99 (2008)

27 Kolodziejski, W. \& Klinowski, J. Kinetics of cross-polarization in solid-state NMR: A guide for chemists. Chem. Rev. 102, 613-628 (2002). 